\title{
Anatomic Variants of Sphenoid Sinuses and Adjacent Structures: A Study of 225 Skull CT Scans at CNHU-HKM in Benin, West Africa
}

\author{
Patricia Yèkpè̀ ${ }^{1,2}$, Djivèdé Akanni ${ }^{3,4^{*}}$, Canicius Ovidio de Souza ${ }^{1,2}$, Sonia Adjadohoun1,2, \\ Miralda Kiki ${ }^{4}$, Kofi-Mensa Savi de Tovè ${ }^{3,4}$, Olivier Biaou ${ }^{1,2}$, Vicentia Boco ${ }^{1,2}$ \\ ${ }^{1}$ Faculty of Health Sciences, University of Abomey Calavi, Cotonou, Benin \\ ${ }^{2}$ Department of Radiology, National and University Teaching Hospital Hubert Koutoukou Maga, Cotonou, Benin \\ ${ }^{3}$ Faculty of Medicine, University of Parakou, Parakou, Benin \\ ${ }^{4}$ Department of Radiology, University Teaching Hospital of Borgou Department, Parakou, Benin \\ Email: *djivakanni@yahoo.fr
}

How to cite this paper: Yèkpè, P., Akanni, D., de Souza, C.O., Adjadohoun, S., Kiki, M., de Tovè, K.-M.S., Biaou, O. and Boco, V. (2018) Anatomic Variants of Sphenoid Sinuses and Adjacent Structures: A Study of 225 Skull CT Scans at CNHU-HKM in Benin, West Africa. Open Journal of Radiology, 8, 181-190.

https://doi.org/10.4236/ojrad.2018.83021

Received: September 2, 2018

Accepted: September 24, 2018

Published: September 27, 2018

Copyright (c) 2018 by authors and Scientific Research Publishing Inc. This work is licensed under the Creative Commons Attribution International License (CC BY 4.0).

http://creativecommons.org/licenses/by/4.0/

\section{c) (i) Open Access}

\begin{abstract}
Objective: This study aimed to describe anatomic variants of sphenoidal sinuses and adjacent structures. Methods: A retrospective and descriptive study was carried out at The National and University Teaching Hospital Hubert Koutoukou Maga (CNHU-HKM), of Cotonou in Benin from November 1st to December 31st. A review of CT scans skull was done for the subjects aged at least 16 years old. Anatomic variants of the sphenoid sinuses and adjacent structures have been investigated. Results: 225 CT scans of skull were analyzed. The sellar type was the most common type of pneumatization of sphenoid sinuses $(74.7 \%)$. Pneumatization of anterior clinoid processes of greater and lesser wings of the sphenoid and of pterygoid processes was observed in $7.1 \% ; 4.6 \% ; 3.3 \%$ and $7.3 \%$; respectively. Protrusion of carotid canals and optic canals, maxillary and vidian nerves were observed in $48.3 \%$; $13.1 \%$; $18 \%$ and 9.5\%; respectively. Conclusion: Risky anatomic variants of the sphenoid sinuses and adjacent structures are also described by CT-scan among Beninese. Before any surgery and to avoid bad outcome, a precise approach of these risky anatomic variants must be carried out by using CT-scan.
\end{abstract}

\section{Keywords}

Anatomic Variants, Sphenoid Sinuses, Skull CT-Scan, Benin

\section{Introduction}

Sphenoid sinuses are deeply located in the skull. They represent the most inac- 
cessible para nasal sinuses [1] [2] [3] [4]. They are described by some authors as being the most variable cavities of the human body [5]. They are surrounded by vital structures such as the internal carotid artery, the optic nerves and the cavernous sinus [5]. The variability of the anatomy of the sphenoid sinuses is well documented [3] [5] [6]. Iatrogenic internal carotid artery or optic nerves injuries are serious complications of trans-sphenoid surgery [4] [7]. The sphenoid sinuses are irregular cavities carved into the body of the sphenoid bone with pneumatization ranging from absence to extension to adjacent structures including anterior and posterior clinoid processes, lesser and greater wings, and processes pterygoids and the clivus [6] [7]. Depending on the extent of sinus pneumatization, bone covering the internal carotid arteries, optic nerves, maxillary nerves, and vidian nerves may be thin or absent, making these structures susceptible to iatrogenic injury [8] [9]. Computed tomography (CT) is the most accurate imaging for studying paranasal sinuses [10] [11] [12] [13]. CT makes reconstructions in the different planes of the space notably in the coronal plane. This plan shows the deep structures progressively as encountered by the surgeon during an intervention. CT also allows a study both in bone window and soft tissue window. Despite the complex anatomy and surgical importance of the anatomic variants of the sphenoidal sinuses, very few studies have been done in Africa. Fasunla et al. [14] in Nigeria; in 2012; showed that surgical anatomic variants of the sphenoid sinuses were also common among black Africans. $38.2 \%$ of their population had a protrusion of the optic canal and $27.3 \%$ a protrusion of carotid canal. This work aimed to study the anatomic variants of sphenoidal sinuses and adjacent structures at the National and University Teaching Hospital Hubert Koutoukou Maga of Cotonou (CNHU-HKM/Cotonou).

\section{Methods}

Our study took place in the radiology department of CNHU-HKM/Cotonou.

A descriptive retrospective study was conducted over two months from November 1st to December 31st, 2017. This study targeted patients who performed a skull CT-scan in the study period.

Included subjects aged at least 16 years and had a skull CT-scan. Sphenoid sinuses are present at birth, but their pneumatization continues until adolescence, when they reach their maximum size [15]. Exhaustive recruitment of all patients was done. Skull CT-scans performed for head trauma, sinuses tumor or nasosinus polyposis, as well as those with a sinus surgical history were not included in the study given the changes that these pathologies are likely to cause on sphenoid sinuses.

The skull CT-scans were performed on EMOTION SIEMENS 16 slide CT-Scanner witch was put in service in December 2013. CT-scans were systematically reviewed in bone window and soft tissue window after multiplanar reconstruction. Sections were in $1 \mathrm{~mm}$ slice thickness.

We studied successively socio-demographic variables such as sex and age; anatomic variants of the sphenoid sinuses such as type of pneumatization of the 
sphenoid sinuses (sellar, presellar and conchal); the number of sphenoid sinuses; pneumatization of anterior clinoid processes, of pterygoid processes, of lesser and greater wings of the sphenoid; protrusion and dehiscence of carotid canal and of optic canal, protrusion and dehiscence of maxillary nerves and vidian nerves.

Protrusion was defined as the presence of at least one third of the canal circumference into the sinus cavity. Dehiscence was defined as the absence of visible bone density separating the sinus from the course of the canal. Protrusion of the vidian nerves was defined as the presence of air density around the nerves [16].

Data collection was done using a survey form prepared for the circumstance. Data analyses were done by using Epi info software Version 3.5.4.

A descriptive analysis of the variables was done. Mean age and standard deviation were calculated. For qualitative variables, frequencies and proportions were calculated. Data has been used in complete confidentiality.

\section{Results}

225 Skull CT-scans were collected. 224 had two sphenoid sinuses and one had a single sphenoid sinus. A total of 449 sphenoid sinuses were examined.

Their age ranged from 16 to 86 years with mean age of 48.8 years \pm 17.2. There was male predominance (58.7\%) with a sex-ratio of 1.42 .

\subsection{Types of Pneumatization of Sphenoid Sinuses}

There were $74.7 \%$ sellar type, $24.9 \%$ presellar type and $0.4 \%$ conchal type (Figure $1)$.

\subsection{Protrusion and Dehiscence of Carotid Canal and Optic Canal}

Protrusion of carotid canal (Figure 2) and optic canal were found in $48.3 \%$ and $13.1 \%$ of patients, respectively. Dehiscence was observed in $10.2 \%$ of patients for carotid canal and 5.8\% for optic canal (Figure 3).

Table 1 showed the detail of protrusion and dehiscence of carotid canal and optic canal.

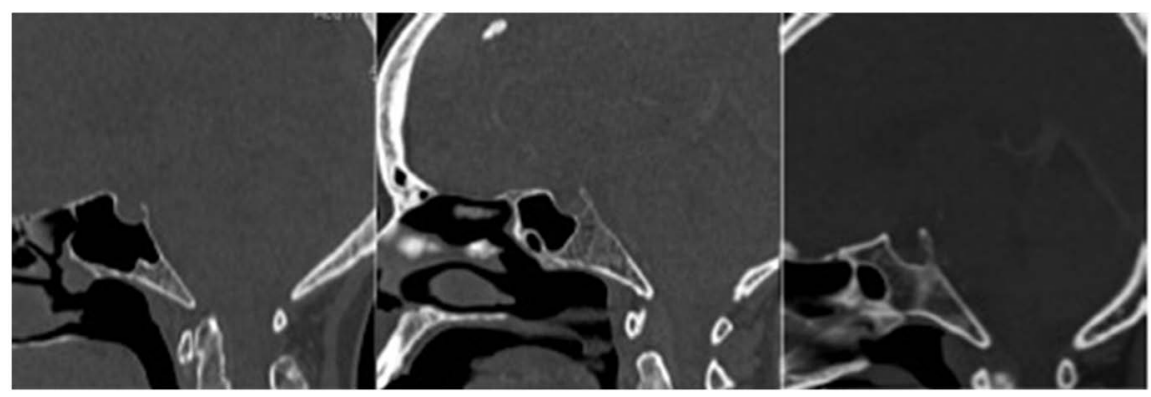

(a)

(b)

(c)

Figure 1. Types of pneumatization: (a) sellar; (b) presellar; (c) conchal, CNHU-HKM, 2017. 


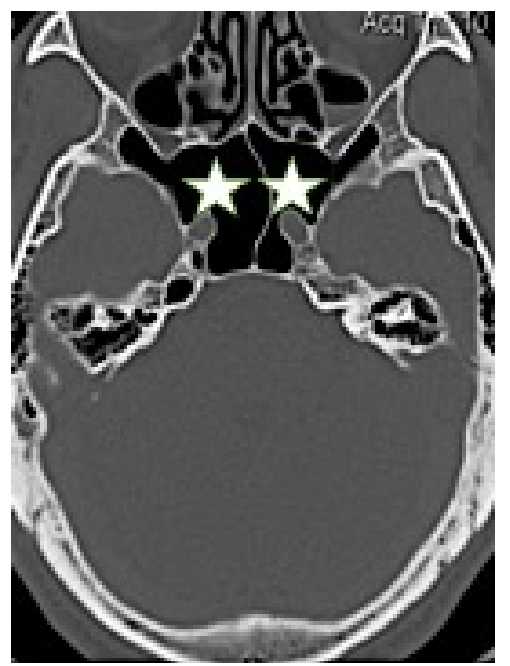

Figure 2. Bilateral protrusion of carotid canal (stars), CNHU-HKM, 2017.

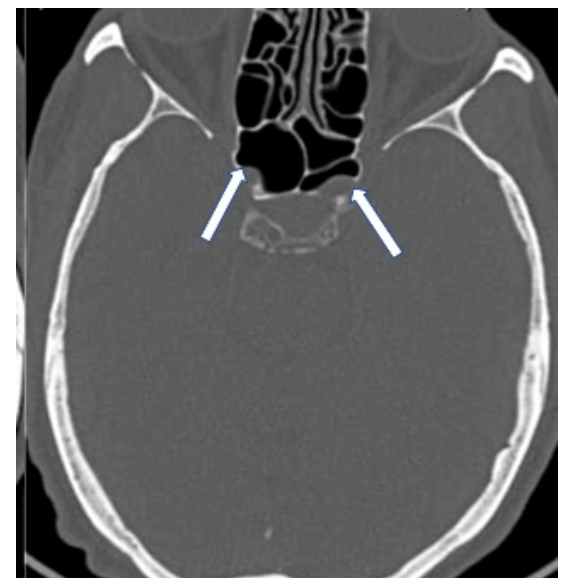

Figure 3. Bilateral dehiscence of optic nerve (arrows), CNHU-HKM, 2017.

Table 1. Prevalence of protrusion and dehiscence of carotid canal and optic canal, CNHU-HKM, 2017.

\begin{tabular}{ccccc}
\hline & \multicolumn{2}{c}{ Carotid Canal } & \multicolumn{2}{c}{ Optic Canal } \\
\cline { 2 - 5 } & $\mathbf{n}$ & $\%$ & $\mathbf{n}$ & $\%$ \\
\hline Protrusion & 4 & & 7 & \\
Rigth Side & 5 & 0.9 & 8 & 1.5 \\
Left Side & 208 & 1.1 & 44 & 9.8 \\
Bilateral & 217 & 46.3 & 59 & 13.1 \\
Total & 48.3 & & \\
Dehiscence & 3 & & 2 & 0.4 \\
Rigth Side & 9 & 0.7 & 4 & 0.9 \\
Left Side & 24 & 2 & 20 & 4.4 \\
Bilateral & 46 & 7.5 & 26 & 5.8 \\
Total & & 10.2 & & \\
\hline
\end{tabular}




\subsection{Protrusion and Dehiscence of Maxillary and Vidian Nerves}

The Protrusion of maxillary and vidian (Figure 4) nerves was found in $18 \%$ and $9.5 \%$ of the patients, respectively. Dehiscence of maxillary nerves was observed in $6 \%$ of patients. Table 2 presented the detail of protrusion and dehiscence of maxillary and vidian nerves.

\subsection{Pneumatization of Adjacent Structures of Sphenoid Sinuses}

Pneumatization of lesser and greater wings of the sphenoid (Figure 5); of anterior clinoid processes (Figure 6) and of pterygoid processes (Figure 7) was found in $4.6 \%, 3.3 \%, 7.1 \%$ and $7.3 \%$ of patients, respectively. The distribution of these data according to their unilateral or bilateral location is presented in Table 3.

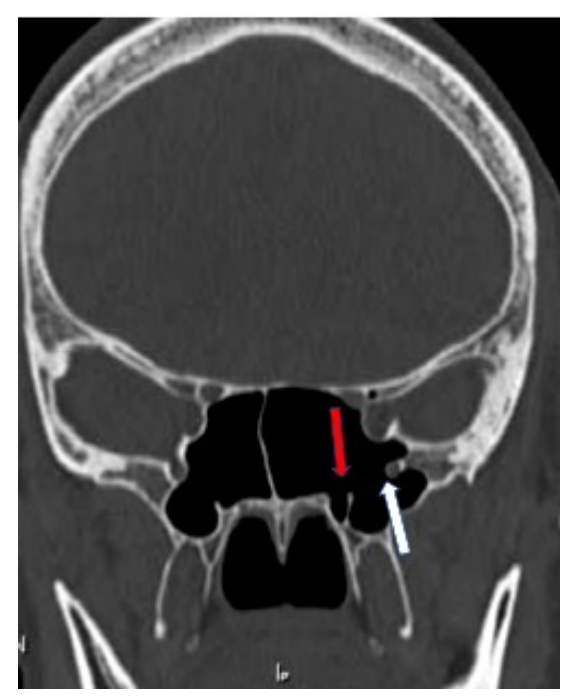

Figure 4. Dehiscence of maxillary nerve (white arrow) and Protrusion of vidian nerve (red arrow), CNHU-HKM, 2017.

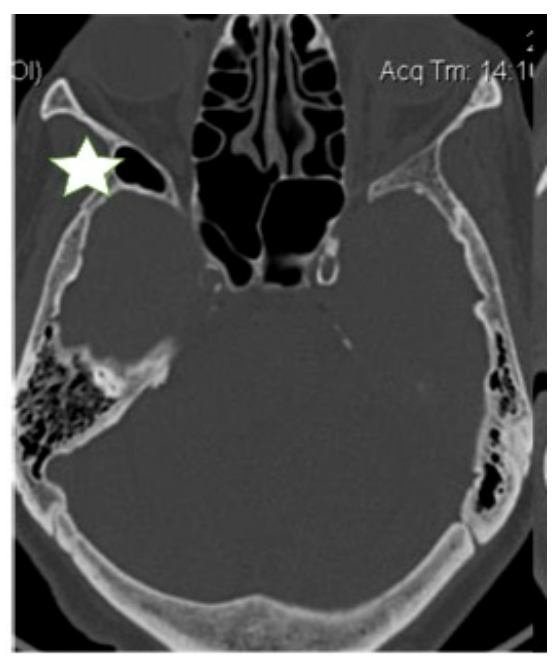

Figure 5. Pneumatization of the right greater wing of sphenoid (star), CNHU-HKM, 2017. 


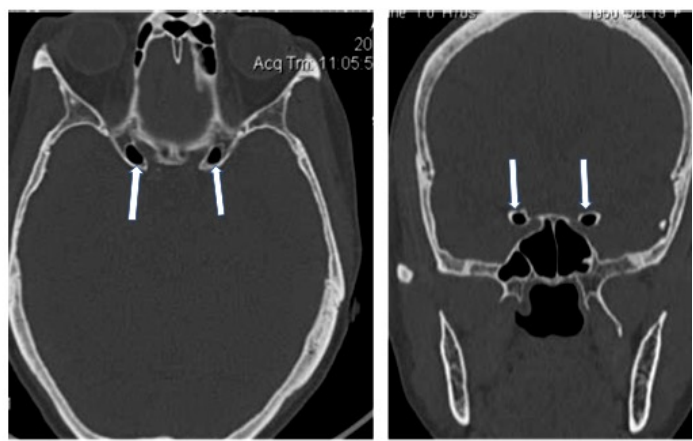

Figure 6. Bilateral pneumatization of anterior clinoid processes (arrow), CNHU-HKM, 2017.

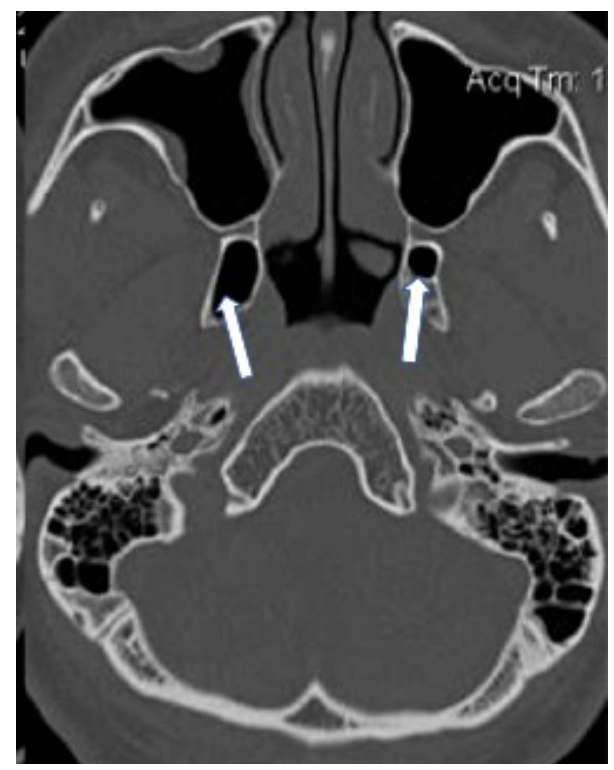

Figure 7. Bilateral pneumatization of pterygoid processes (arrow), CNHU-HKM, 2017.

Table 2. Prevalence protrusion and dehiscence of maxillary and vidian nerves, CNHU-HKM, 2017.

\begin{tabular}{ccccc}
\hline & \multicolumn{2}{c}{ Maxillary nerves } & \multicolumn{2}{c}{ Vidian nerves } \\
\cline { 2 - 5 } & $\mathbf{n}$ & $\%$ & $\mathrm{n}$ & $\%$ \\
\hline Protrusion & 3 & & 3 & 0.7 \\
Rigth Side & 6 & 0.7 & 2 & 0.4 \\
Left Side & 72 & 1.3 & 19 & 8.4 \\
Bilateral & 81 & 18 & 24 & 9.5 \\
Total & 2 & & & - \\
Dehiscence & & 0.4 & - & - \\
Rigth Side & 5 & 1.1 & - & - \\
Left Side & 20 & 4.4 & - & - \\
Bilateral & 27 & 6 & - & \\
Total & 5 & &
\end{tabular}


Table 3. Prevalence of pneumatization of adjacent strutures of sphenoid sinuses, CNHU-HKM, 2017.

\begin{tabular}{ccccc}
\hline & Rigth Side & Left Side & Bilateral & Total \\
\cline { 2 - 5 } & $\mathbf{n}(\%)$ & $\mathbf{n}(\%)$ & $\mathbf{n}(\%)$ & $\mathbf{n}(\%)$ \\
\hline Greater Wing & $3(0.7)$ & $4(0.9)$ & $14(3.1)$ & $21(4.6)$ \\
Lesser Wing & $1(0.2)$ & $2(0.4)$ & $12(2.7)$ & $15(3.3)$ \\
Clinoid & $9(2)$ & $7(1.5$ & $16(3.6)$ & $32(7.1)$ \\
Pterygoid & - & $5(1.1)$ & $28(6.2)$ & $33(7.3)$ \\
\hline
\end{tabular}

\section{Discussion}

The current study aimed to describe the anatomic variants of sphenoid sinuses and adjacent structures. The findings help to characterize the anatomic variants of sphenoid sinuses and adjacent structures amongst Beninese population.

\subsection{Type of Pneumatization of Sphenoid Sinuses}

In our series, sellar type pneumatization was the most common, $74.7 \%$. In the literature, variable proportions of different types of pneumatization have been reported. Sellar type was the most frequent. Wang et al. [6] reported in 2010, $98 \%$ of sellar type pneumatization and $2 \%$ for the presellar type. Other authors have found prevalence closer to ours. Notably Lu et al. [8] in China and El Kammash et al. [9] in Egypt, which reported $63.5 \%$ and $85.7 \%$ of sellar type pneumatization; $28.5 \%$ and $12.6 \%$ of presellar pneumatization respectively.

\subsection{Protrusion and Dehiscence of Carotid Canal and Optic Canal}

In the literature, there is great variability in the prevalence of protrusion and dehiscence of carotid canal and optic canal. This variability could be due to the criteria considered to define them. In our study, we considered as a protrusion the presence of at least one third of the canal circumference in the sinus cavity and dehiscence was defined as the absence of visible bone density separating the sinus from the course of the canal. In their work, Fasunla et al. [14], Sirikci et al. [11], Unal et al. [5] recognized protrusion as the presence of more than half of the canal circumference in the sinus. For Hewaidi et al. [12], the presence of the canal in the sinus cavity to any degree was sufficient to define protrusion. Fasunla, Sirikci, Unal found respectively $27.3 \%, 26.1 \%$ and $30.3 \%$ for the prevalence of carotid canal protrusion. Our rate of $48.3 \%$ was close to that of Hewaidi which was $41 \%$. This great variability is also observed at the optic canal. The prevalence of the protrusion of optic canal varies from $8 \%$ to $70 \%$ according to the authors [13]. In our series the prevalence of the optical canal protrusion was $13.1 \%$. This wide range of prevalence may also indicate that the relationship of the carotid canal or the optic canal to the sphenoidal sinus is different between races and ethnic groups, but the variability of the definition criteria does not help to confirm this hypothesis. 
If the surgeon operating the sphenoid sinus is not aware of the dehiscence or protrusion of the carotid canal, a wound of this vessel, even a small one, can be fatal, as it is barely possible to control the bleeding of an internal carotid artery injured in the sphenoidal sinus. Also, neurological sequelae may be unavoidable. Similarly, sphenoiditis can also make internal carotid artery vulnerable [11].

In protrusion or dehiscence of optic canal, optic nerves injury may occur in the event of surgical trauma or as a complication of sphenoid sinusitis. The risk of blindness is high if the surgeon injures the nerve in the sinus [17]. Also, visual deficits can result from an infection of the sphenoid or a mucocele from compressing the optic canal. Compression of the optic nerve can cause ischemia and congestion of the ophthalmic vein. In addition, the optic canal is where the optic nerve is least vascularized, making it very susceptible to injury [18].

\subsection{Protrusion and Dehiscence of Maxillary and Vidian Nerves}

Protrusion prevalence of maxillary and vidian nerves observed in our series was significantly lower than those found in the literature. We observed protrusion of the maxillary nerve in $18 \%$ of patients. Hewaidi et al. [12], Unal et al. [5], reported a prevalence of $24.3 \%$ and $30.3 \%$, respectively.

We found protrusion of vidian nerve in $9.5 \%$ of our patients. Hewaidi et al. [12] found this protrusion in $27 \%$ of cases.

The divergence between these prevalences may reflect ethnic differences between the populations studied.

In endoscopic surgery, knowledge of these variants will contribute to improved outcomes and decrease the complications of sinus surgeries [9].

\subsection{Pneumatization of Adjacent Structures of Sphenoid Sinuses}

For Hewaidi et al. [12], it is likely that thin CT scan sections are more precise for the detection of pneumatization of the adjacent structures to the sphenoid sinuses. Thick slice may underestimate these anatomic variants especially when they are not joined. In his series, on $2 \mathrm{~mm}$ slice thickness, $20 \%$ had pneumatization of greater wings, $15.3 \%$ had pneumatization of anterior clinoid processes, and $29 \%$ had pneumatization of pterygoid processes. In our study, on $1 \mathrm{~mm}$ slice thickness, we found a much lower prevalence of pneumatization of adjacent structures to the sphenoid sinuses. $4.6 \%$ of our patients had pneumatization of greater wings, $7.1 \%$ had pneumatization of anterior clinoid processes, and 7.3\% had pneumatization of pterygoid processes. On $3 \mathrm{~mm}$ slice thickness, Lane and Bolger [19] and Unal et al. [5] found a prevalence of $13 \%$ and $24.1 \%$ for pneumatization of anterior clinoid processes, respectively. These results suggest that beyond the thickness of the sections, the wide variability in the prevalence of pneumatization of adjacent structures can also be attributed to ethnic differences in the populations studied. The pneumatization of the pterygoid process, when present, is an important route for access to the skull base. It allows, for example, extensive transnasal endoscopic approaches to reach the pterygoid process through the medial part of the posterior maxillary wall [17]. These techniques 
may provide a pathway for endoscopic repair of cerebrospinal fluid leaks and for endoscopic biopsy of skull base lesions. Such information may be important for the surgeon in preoperative planning for skull base surgery. Also, the pneumatization of the pterygoid process thins the bone floor of the scaphoid fossa, resulting in an intimate relationship between the sinus and the auditory tube [20].

\subsection{Limitation of the Study}

The number of cases and the absence of additional readers to compare the results of the first reading are limits to this study.

\section{Conclusion}

Anatomic variants of the sphenoid sinuses and adjacent structures were varied and frequent. There was a wide range of prevalence of anatomic variants in the literature. This variability could be due to ethnic differences between the populations studied. Knowledge of these variants is important for the surgeon to choose the best routes and to avoid serious iatrogenic lesions such as hemorrhage and blindness.

\section{Conflicts of Interest}

The authors have no conflict of interest to declare.

\section{Authors' Contributions}

Akanni D conceived the study. de Souza OC collected the data. Akanni D and de Souza analyzed and drafted the manuscript. All authors approved the final version of the article.

\section{References}

[1] Cappabianca, P., Cavallo, L.M., Colao, A., Del Basso De Caro, M., Esposito, F., Cirillo, S., et al. (2002) Endoscopic Endonasal Transsphenoidal Approach: Outcome Analysis of 100 Consecutive Procedures. Min-Minim Invasive Neurosurg, 45, 193-200. https://doi.org/10.1055/s-2002-36197

[2] Casselman, J.W. (2003) The Sphenoid Bone: Anatomy. Journal of Neuroradiology, 30, 201-210.

[3] Hamid, O., El Fiky, L., Hassan, O., Kotb, A. and El Fiky, S. (2008) Anatomic Variations of the Sphenoid Sinus and Their Impact on Trans-sphenoid Pituitary Surgery. Skull Base, 18, 9-15.

[4] Sareen, D., Agarwal, A.K., Kaul, J.M. and Sethi, A. (2005) Study of Sphenoid Sinus Anatomy in Relation to Endoscopic Surgery. International Journal of Morphology, 23, 261-266. https://doi.org/10.4067/S0717-95022005000300012

[5] Unal, B., Bademci, G., Bilgili, Y.K., Batay, F. and Avci, E. (2006) Risky Anatomic Variations of Sphenoid Sinus for Surgery. Surgical and Radiologic Anatomy, 28, 195-201. https://doi.org/10.1007/s00276-005-0073-9

[6] Wang, J., Bidari, S., Inoue, K., Yang, H. and Rhoton, A. (2010) Extensions of the Sphenoid Sinus. Neurosurgery, 66, 797-816. https://doi.org/10.1227/01.NEU.0000367619.24800.B1 
[7] Kantarci, M., Karasen, R.M., Alper, F., Onbas, O., Okur, A. and Karaman, A. (2004) Remarkable Anatomic Variations in Paranasal Sinus Region and Their Clinical Importance. European Journal of Radiology, 50, 296-302. https://doi.org/10.1016/j.ejrad.2003.08.012

[8] Lu, Y., Pan, J., Qi, S., Shi, J., Zhang, X. and Wu, K. (2011) Pneumatization of the Sphenoid Sinus in Chinese: The Differences from Caucasian and Its Application in the Extended Transsphenoidal Approach. Journal of Anatomy, 219, 132-142. https://doi.org/10.1111/j.1469-7580.2011.01380.x

[9] ELKammash, T.H., Enaba, M.M. and Awadalla, A.M. (2014) Variability in Sphenoid Sinus Pneumatization and Its Impact upon Reduction of Complications Following Sellar Region Surgeries. The Egyptian Journal of Radiology and Nuclear Medicine, 45, 705-714. https://doi.org/10.1016/j.ejrnm.2014.04.020

[10] Dubrulle, F., Martin-Duverneuil, N. and Moulin, G. (2010) Imagerie en ORL. Elsevier Masson, Issy-les-Moulineaux, France, 448 p.

[11] Şirikci, A., Bayazıt, Y.A., Bayram, M., Mumbuç, S., Güngör, K. and Kanlikama, M. (2000) Variations of Sphenoid and Related Structures. European Radiology, 10, 844-848. https://doi.org/10.1007/s003300051016

[12] Hewaidi, G. and Omami, G. (2008) Anatomic Variation of Sphenoid Sinus and Related Structures in Libyan Population: CT Scan Study. Libyan Journal of Medicine, 3, 128-133. https://doi.org/10.3402/ljm.v3i3.4775

[13] Dessi, P., Moulin, G., Castro, F., Chagnaud, C. and Cannoni, M. (1994) Protrusion of the Optic Nerve into the Ethmoid and Sphenoid Sinus: Prospective Study of 150 CT Studies. Neuroradiology, 36, 515-516. https://doi.org/10.1007/BF00593511

[14] Fasunla, A., Ameye, S., Adebola, O., Ogbole, G., Adeleye, A. and Adekanmi, A. (2012) Anatomical Variations of Sphenoid Sinus and Nearby Neurovascular Structures Seen on Computed Tomography of Black Africans. East and Central African Journal of Surgery, 17, 57.

[15] Gray, H. (1989) Gray's Anatomy. Churchill Livingstone, Edinburgh, 376-377.

[16] Ouardi, F., Idrissi, A., El Bennal, N., Aineb, I. and Abdelouafi, A. (2009) ORL-WS-25 Sinus Sphenoidal: Variantes Anatomiques et Leurs Risques. Journal de Radiologie, 90, 1563.

[17] Maniglia, A.J. (1989) Fatal and Major Complications Secondary to Nasal and Sinus Surgery. The Laryngoscope, 99, 276-283. https://doi.org/10.1288/00005537-198903000-00008

[18] Sofferman, R.A. and Harris, P. (1995) Mosher Award Thesis. The Recovery Potential of the Optic Nerve. The Laryngoscope, 105, 1-38.

[19] Lane, A.P. and Bolger, W.E. (2002) Endoscopic Transmaxillary Biopsy of Pterygopal-Atine Space Masses: A Preliminary Report. American Journal of Rhinology \& Allergy, 16, 109-112. https://doi.org/10.1177/194589240201600207

[20] Vidić, B. (1968) The Postnatal Development of the Sphenoidal Sinus and Its Spread into the Dorsum Sellae and Posterior Clinoid Processes. American Journal of Roentgenology, 104, 177-183. https://doi.org/10.2214/ajr.104.1.177 